\title{
CULTURAL AND HUMAN DIVERSITY: DOMAIN GUEST EDITORS
}

\section{Lloyd Bullard, MEd}

Lloyd Bullard has over 27 years of experience working within the human services field. He is considered a national expert in residential care, restraint and seclusion reduction, cultural competence and racial disproportionality, and supervisory training. Mr. Bullard has developed and managed numerous national and local programs and initiatives. He is the founder and CEO of LB International Consulting, LLC, (LBIC) and provides consultation and training services to private and public agencies serving children, youth, families, and individuals. Prior to launching LBIC he spent ten years working for the Child Welfare League of America (CWLA) where, in addition to serving as a senior consultant, he held the director position for Residential Care, Cultural Competence and Racial Disproportionality, and Best Practices to Reduce the Use of Restraint and Seclusions. LBIC is a member of the Alliance for Children and Families' Intellectual Capital Division.

Mr. Bullard is a member of the Substance Abuse \& Mental Health Services Administration (SAMHSA) Building Bridges Initiative's Workgroup on Cultural and Linguistic Competence and a member of the Child Welfare League of America (CWLA) National Advisory Committee on Residential Care and the CWLA National Advisory Committee on Cultural Competence. He is an active member of the District of Columbia's Task Force on Human Trafficking, is on the Advisory Board for the North American Certification Project (NACP), has served as an Independent Consultant for the Child Welfare League of America and Cornell University Residential Project, and serves as Board Chairman for African American Adoptions, Inc.

Mr. Bullard has published and edited over thirty books, chapters, position papers, guidelines, and articles on cultural competency, restraint and seclusion reduction, recruitment and retention, racial disproportionality and disparity of outcomes, supervisory skills, and residential care. He also served as an Adjunct Professor for Concordia University, St. Paul, MN.

\section{Deborah K. Green, MSW, MAC, CDVC-III, CCJS, BEI-1}

Deborah is a services program administrator for DFPS Child Protective Services (CPS) in Houston, Texas with over 30 years of experience in the field of Child Welfare. Ms. Green is also the CPS Regional Liaison to the Texas Youth Commission (TYC) and Texas Juvenile Probation Commission (TJPC). Throughout her career, she 
has worked in every area of Child Welfare, holding multiple leadership and management positions such as leading the state's Disproportionality initiative as the first Texas Disproportionality Division Administrator, Regional Best Practice Program Director, and CPS Program Director for Investigations, Family Based Safety Services, Substitute Care, Adoption Prep, and Preparation for Adult Living.

Ms. Green's experience includes administration, developing, directing, oversight, and management of several state Child Protection program areas including: Family Group Decision Making, Family Team Meetings, Family Group Conference, Circles of Support, Preparation for Adult Living, Permanency, Education Specialists, and the I See You Conservatorship program. Ms. Green lectures and presents on prevention and intervention with families, permanency, and transitional youth services for adolescents that have been "most difficult to serve" as they transition out of the Child Welfare System into adulthood. Ms. Green is published in journals and articles and recently co-edited Challenging Racial Disproportionality in Child Welfare: Research, Policy, and Practice (2011). Ms. Green advocates for all children and all families on a daily basis.

\section{Peter R. Correia III, MSW}

Peter is director of The University of Oklahoma's National Resource Center for Youth Services (NRCYS). He has a master's in social work from Boston University and was named a George Edmund Haynes Fellow by the National Urban League in New York.

At NRCYS he is responsible for the overall operations of several state and national programs that provide training and technical assistance to child welfare, community-based agencies, and tribes. Peter has more than 30 years' experience in the areas of child welfare, youth services, and cultural competence. As a practiced trainer and facilitator, Peter has presented workshops and provided technical assistance to child welfare and youth service agencies across the United States. He is an expert resource in the areas of Independent Living, Permanency Planning, Cultural Competency, and Youth Development as well as other issues in the child welfare system. Peter has presented numerous workshops on cultural competency over the years and authored a diversity curriculum entitled, “Differences: Building Bridges or Walls”.

In 2006, he was presented with the Champion of Children Awards by the Foster Care Association of Oklahoma - an award presented to outstanding Oklahomans honored for their special service and care for foster and adopted children and their families. 


\section{COMPETENCY III: APPLIED HUMAN DEVELOPMENT}

In the domain of "Applied Human Development", the section editors sought out theory, research, and practice contributions that emphasize perspectives of positive human development grounded in growth and change over a life trajectory. Our selections focus mostly on adolescents and give priority to readings that acknowledge voluntary youth participation, proactive engagement, and personal authorship of one's individual growth and learning. They present an explicit perspective of applied youth development grounded in resilience theory, focused on protective factors, and conceptually based on competence and strength-building strategies. As such, they are relevant to workers in many care and educational sectors ranging from residential and clinical care to community-based youth development programs. Finally, the concept of an ecology of human development is fundamental for child and youth work practice; therefore, attention to context and relationships given throughout the selections.

Gisela Konopka's classic, "Requirements for Healthy Development of Adolescent Youth" (1973), explicitly addresses principles of human rights as the foundation for a developmental view of adolescence and adolescent needs that is relevant to advocates, practitioners, researchers, policymakers, and educators committed to work with young people as healthy, respected, and contributing participants in relationships, families, and communities. She presents adolescence as the age of commitment, challenging all the labels, stereotypes, and easy clichés society often associated with the second decade of life.

Reed Larson's "Toward a Psychology of Positive Youth Development" (2000) illustrates the bridging between research and practice. It shows how applied research findings are used to increase intentionality in program design and in practice, to establish realistic goals for youth programs, and to expand the crucial role youth programs and activities play as developmental contexts for positive youth development. Larson's references are a rich resource for child and youth care workers who wish to know the leading thinkers and researchers who have influenced our understandings of work in applied human development.

Our pick of Michael Resnick's research review, "Protective Factors, Resiliency, and Healthy Youth Development" (2000), makes the contemporary case that understanding of resiliency theory, research on protective factors, and practice approaches grounded in youth development philosophies are at the heart of youth work today. His review illustrates that scientific inquiry has begun to catch up with the long-held practitioner understanding that it takes both reduction of risk factors and promotion of protective factors to find the answer to what works in fostering the healthy development of young people. (Editor Note: Unfortunately the editors were unable to secure the necessary permissions to reprint this article. A complete reference can be found in the Resource Readings for this section.) 
In our field, practice came before research. Child and youth care work existed in myriad places, spaces, and contexts long before the practice was subject to scientific inquiry. This has implications even today. The established scholarly disciplines such as developmental psychology, medicine, social work, and public health began to apply their own scientific standards for research to their inquiry into child and youth care practice. Consequently, we find abundant research that is based on the assumptions of young people as subjects of experiments, clients of systems of correction and prevention, and problems to be fixed. Konopka, Resnick, and Larson all bring a perspective of children and young people as people with strengths and problems living in relationships and environments with real world strength, deficits, limitations, and opportunities. Over 50 years they have paved the way for a field we hold up today as fundamentally grounded in reciprocity and respect in power and relationships whether the setting is an afterschool program, a group home, a sports team, a homeless shelter, or a service-learning project.

\section{Applied Human Development Domain Editors}

Joyce Walker, PhD, Professor Emerita

University of Minnesota

Dale Blyth, $P h D$

University of Minnesota

James Anglin, $P h D$

University of Victoria

Michael Nakkula, EdD

University of Pennsylvania 